\title{
Tracking the target in colonic diverticular bleeding using red dichromatic imaging
}

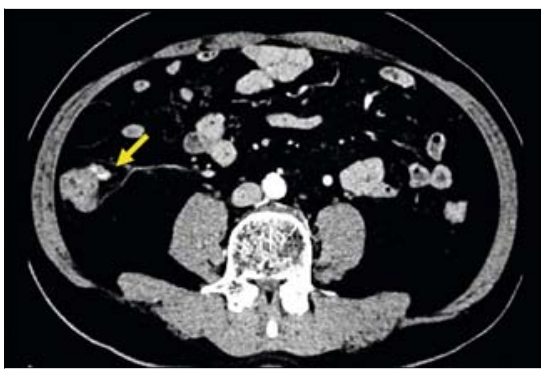

- Fig. 1 Contrast-enhanced computed tomography at admission. Extravasation was observed in the ascending colon (yellow arrow).

"Red" is indistinguishable from "red." Pooling of blood in the colon is often encountered during urgent colonoscopy and is reportedly useful for detecting the lesion responsible for acute lower gastrointestinal bleeding [1]. However, discerning active or recent bleeding is cumbersome in an environment containing blood that has accumulated over various time points. The novel image-enhanced endoscopic technique, red dichromatic imaging (RDI), may overcome this problem. It clearly demarcates active bleeding from the surrounding residual blood based on the color-contrast principle (i. e. the difference in the target's hemoglobin concentration and thickness) [2]. A 66-year-old man was admitted to our hospital with hematochezia. Contrastenhanced computed tomography revealed extravasation in the ascending colon ( Fig. 1). Urgent colonoscopy was performed using the CF-HQ290I enteroscope (equipped with a waterjet) and EVIS X1 device (Olympus Co., Tokyo, Japan) after bowel preparation with polyethylene glycol (PEG). Massive blood pooling was observed in the ascending colon ( $\vee$ Fig. 2 a), which hindered endoscopic vision and obscured the bleeding points. Upon switching from white-light endoscopy (WLE) to the RDI mode, an amber stream, clearly demarcated from the translucent surroundings, was identified at the medial aspect of the ascending

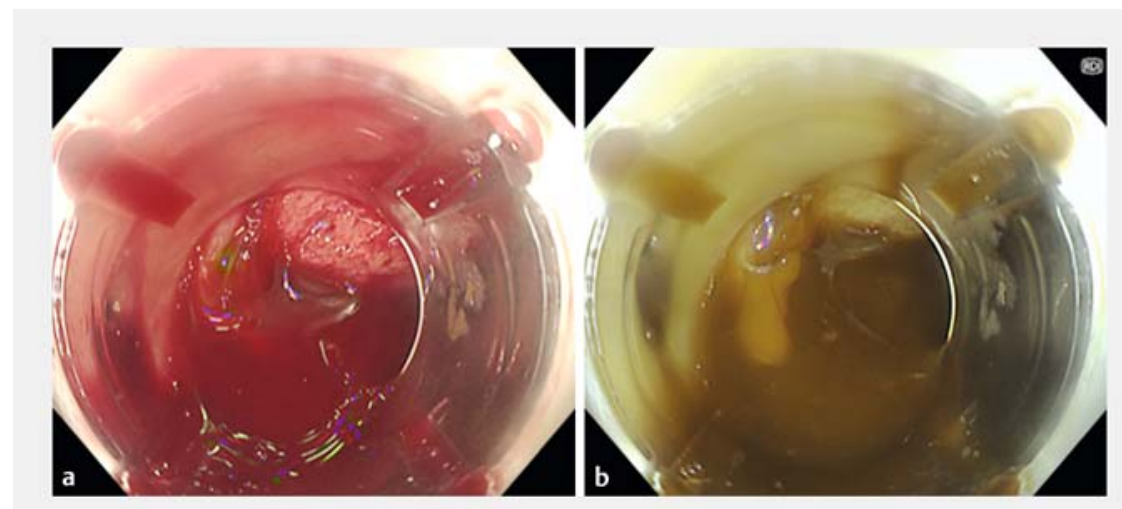

- Fig. 2 Endoscopic view of the ascending colon. a On white-light endoscopy, evidence of recent bleeding was difficult to obtain owing to the surrounding environment consisting of pooled residual blood. $\mathbf{b}$ Red dichromatic imaging enhanced the evidence of recent bleeding and easily distinguished it from the surrounding environment.

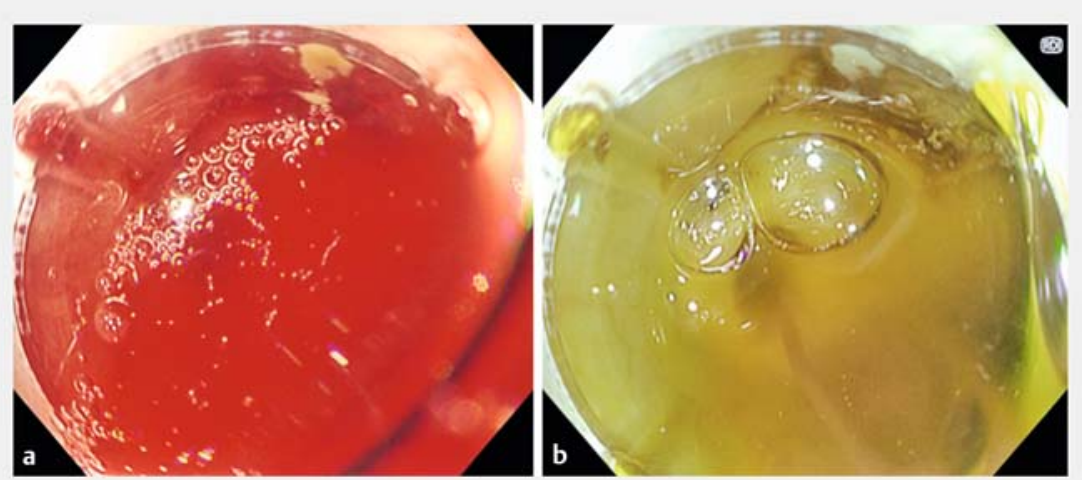

- Fig. 3 Causative diverticulum with active bleeding. a The blood stream was difficult to identify using white-light endoscopy. $\mathbf{b}$ The blood stream was clearly depicted amidst blood pooling on the red dichromatic imaging mode.

colon ( $\downarrow$ Fig. $\mathbf{2}$ b). The amber stream was found to be fresh blood or active bleeding, while the surrounding environment contained blood diluted with PEG. The causative diverticulum with active bleeding from the dome was successfully identified on RDI, having been obscured by residual blood on WLE ( Fig. 3, \ Video 1). Hemostasis was successfully achieved using endoscopic band ligation. The patient was discharged 5 days after treatment without any rebleeding or adverse events.
This case demonstrated the clinical utility of the RDI mode, which enhances only fresh blood that is otherwise missed on WLE and may help to identify the lesion responsible for bleeding, especially in the presence of residual blood in the colon.

Endoscopy_UCTN_Code_TTT_1AQ_2AB 


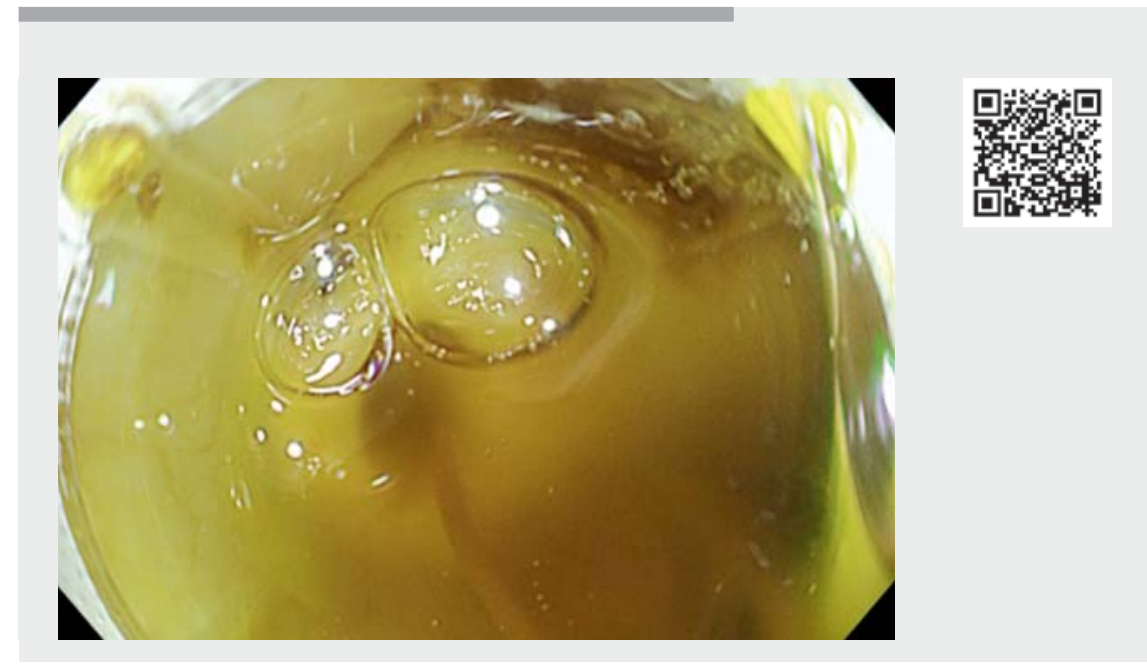

Video 1 Pooled blood hindered endoscopic vision and identification of the exact bleeding point. Red dichromatic imaging revealed active or recent bleeding by providing a vivid color contrast from the surrounding residual blood.

\section{Competing interests}

The authors declare that they have no conflict of interest.

The authors

Masachika Saino, Taiki Aoyama ${ }^{\odot}$, Akira Fukumoto, Kenjiro Shigita, Naoki Asayama, Shinichi Mukai, Shinji Nagata Department of Gastroenterology, Hiroshima City Asa Citizens Hospital, Hiroshima, Japan

\section{References}

[1] Niikura R, Nagata N, Yamada A et al. Efficacy and safety of early vs elective colonoscopy for acute lower gastrointestinal bleeding. Gastroenterology 2020; 158: 168-175

[2] Tanaka H, Oka S, Tanaka S. Endoscopic hemostasis for spurting duodenal bleeding using dual red imaging. Dig Endosc 2017; 29: $816-817$

\section{Bibliography}

Endoscopy 2021; 53: E425-E426

DOI 10.1055/a-1327-1701

ISSN 0013-726X

published online 27.1.2021

(c) 2021. Thieme. All rights reserved.

Georg Thieme Verlag KG, Rüdigerstraße 14, 70469 Stuttgart, Germany

\section{ENDOSCOPY E-VIDEOS \\ https://eref.thieme.de/e-videos}

\section{Taiki Aoyama, MD, PhD}

Department of Gastroenterology, Hiroshima City Asa Citizens Hospital,

2-1-1 Kabeminami, Asakita-ku, Hiroshima 731-0293, Japan

t-aoyama@asa-hosp.city.hiroshima.jp 